\title{
Changes in the Histology of Cold-Hardened Oat Crowns during Recovery from Freezing
}

David P. Livingston III,* Shyamalrau P. Tallury, Ramaswamy Premkumar, Shirley A. Owens, and C. Robert Olien

\begin{abstract}
The survival of cereal crops during winter depends primarily on the ability of tissue in the crown to withstand various stresses encountered during freezing. Freeze-induced damage to specific regions of oat (Avena sativa $L$.) crowns was evaluated by sectioning plants at various stages of recovery after they had been grown and frozen under controlled conditions. Our results confirmed those reported for barley (Hordeum vulgare L.) and wheat (Triticum aestivum L.) that the apical meristem was apparently the tissue in the crown most tolerant of freezing. Photographs of sections during recovery provided evidence that the apical meristem within the crown survived freezing in plants that were rated as nonsurvivors. Closer examination revealed abnormal nuclei in many cells of plants that had been frozen. These cells with condensed and dark red chromatin resembled the description of nuclear pycnosis found in mammalian cells damaged by radiation, extreme abiotic stress, and various carcinogens. The crown meristem complex was separated from the crown and fractionated into two regions: the upper portion of the crown meristem complex, called the apical region, and the lower portion called the crown core. The dry weight of both the apical region and crown core increased during cold-hardening but the increase in dry weight was higher in the crown core than in the apical region. During cold-hardening the percentage of total water freezing at $-2^{\circ} \mathrm{C}$ became lower and after 3 wk was 50 and $47 \%$ in the apical region and the crown core, respectively. The initial freezing rate of the apical region was higher than that of the crown core and reached equilibrium about $2 \mathrm{~h}$ earlier than the crown core. Differences are discussed in relation to the freezing survival of specific tissue.
\end{abstract}

$\mathrm{W}$ INTER CEREALS have a distinct advantage over those that are spring-planted. Because they are planted in the fall, they emerge before it is possible to plant in the spring and are therefore ready to harvest before a spring-sown crop. This allows the fall-planted crop to avoid the potential effects of a hot and dry summer. In winter cereals, under some conditions, this can result in yields that are 50 to $75 \%$ higher than that of a spring-planted crop (Shands and Chapman, 1961). However, a major limitation to growing fall-planted cereals is their susceptibility to freezing conditions during winter; this is particularly true of oat, the least winterhardy of the winter cereals (Livingston, 1996).

The ability to recover from freezing is enhanced by

D.P. Livingston III and R. Premkumar, USDA and North Carolina State Univ., 840 Method Rd., Unit 3, Raleigh, NC 27695. S.P. Tallury, North Carolina State Univ., 840 Method Rd., Unit 3, Raleigh, NC 27695. S.A. Owens, Center for Advanced Microscopy, B7 CIPS Bldg., Michigan State Univ., East Lansing, MI 48824. C.R. Olien, Dep. of Crop and Soil Sciences, Plant and Soil Sciences Bldg., Michigan State Univ., East Lansing, MI 48824. Received 1 Oct. 2004. *Corresponding author (dpl@unity.ncsu.edu).

Published in Crop Sci. 45:1545-1558 (2005).

Crop Physiology and Metabolism

doi:10.2135/cropsci2004.0579

(C) Crop Science Society of America

677 S. Segoe Rd., Madison, WI 53711 USA a period of low, above-freezing temperatures, termed cold-hardening. Cold-hardening is a critical event in the over-wintering physiology of plants (Levitt, 1980). Almost every biochemical adaptation during cold-hardening has been either positively or negatively correlated with an increase in freezing tolerance (Steponkus, 1978). However, it has been difficult to establish cause and effect between a particular biochemical adaptation during cold-hardening and increased freezing tolerance.

In winter cereals the lower part of the stem, referred to as the crown, contains meristems that produce new growth in the spring as well as a combination of cells that act as a node between root and stem (Avery, 1930). Recovery in the spring depends largely on the ability of these meristematic regions to withstand stresses resulting from water redistribution during freezing-thawing and by the proliferation of microorganisms during recovery (Olien, 1964; Marshall, 1965; Tanino and McKersie, 1985; Shibata and Shimada, 1986; Pearce et al., 1998).

Little information is available on the development and composition of crown tissue in winter cereals. Histological documentation of freeze damage and resulting degeneration, or recovery, of specific tissue or cells in the meristematic regions of the crown may provide insight into the cause and effect of documented biochemical adaptation during cold-hardening. Previous reports of differential survival of various tissues in the crown (Olien, 1964; Tanino and McKersie, 1985; Shibata and Shimada, 1986; Pearce et al., 1998) provided illustrations of recovering tissue that were relatively indistinct and difficult to interpret. The objective of this study was to chronicle histological changes in oats during coldhardening and to observe how specific tissues within the crown were affected by freezing. In addition, the crown was separated into two fractions to determine physical differences between specific tissues during coldhardening.

\section{MATERIALS AND METHODS}

\section{Plant Culture}

Seeds of oat (cv. 'Wintok') were grown in Scotts Metromix 580 (Scotts-Sierra Horticultural Products Co., Marysville, OH) in plastic tubes $(2.5-\mathrm{cm}$ diameter $\times 16-\mathrm{cm}$ height $)$ with holes in the bottom to allow drainage. The tubes were suspended in a grid that held 100 tubes. Plants were watered three times weekly with a complete nutrient solution (Livingston, 1991) and flushed three times weekly with tap water. Plants were grown for $5 \mathrm{wk}$ at $13^{\circ} \mathrm{C}$ day and $10^{\circ} \mathrm{C}$ night temperatures with a 10 -h photoperiod at $280 \mu \mathrm{mol} \mathrm{m} \mathrm{m}^{-2} \mathrm{~s}^{-1}$ of photosynthetically active radiation ( $80 \%$ cool fluorescent and $20 \%$ incandescent). After $5 \mathrm{wk}$, plants were transferred to a chamber at $3^{\circ} \mathrm{C}$ with a $10-\mathrm{h}$ photoperiod at $300 \mu \mathrm{mol} \mathrm{m} \mathrm{m}^{-2} \mathrm{~s}^{-1}$. Plants remained under these conditions for $3 \mathrm{wk}$; this constituted cold-hardening. Photographs were taken of nonhardened (Fig. 1A) and cold-hardened plants (Fig. 1B).

Abbreviations: CM, crown meristem. 

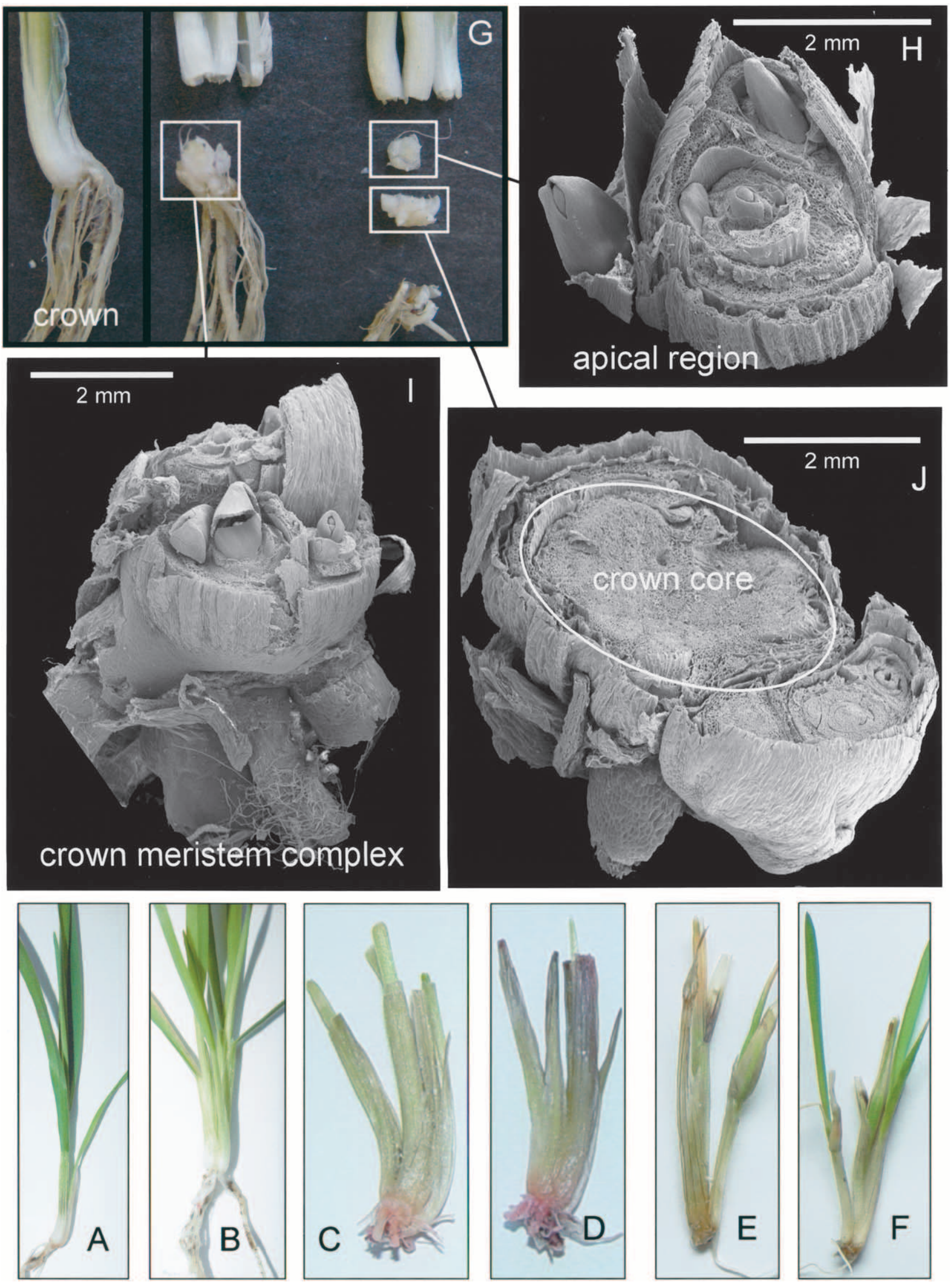


\section{Freeze Tests}

After cold-hardening, crowns were separated and removed from each plant by trimming roots and shoots. The crowns were inserted into slits made in circular moist sponges at $2^{\circ} \mathrm{C}$, placed in a plastic bag to prevent desiccation, inoculated with ice shavings to initiate freezing and prevent super-cooling, and then placed in a freezer at $-3^{\circ} \mathrm{C}$. Crowns were kept at $-3^{\circ} \mathrm{C}$ for $3 \mathrm{~d}$ to provide hardening at below-freezing temperatures (subzero-hardening) and then the temperature in the freezer was reduced to -11 or $-13^{\circ} \mathrm{C}$ at $1^{\circ} \mathrm{C}$ per hour and held at this temperature for $3 \mathrm{~h}$. The temperature was then raised to $2^{\circ} \mathrm{C}$ at $2^{\circ} \mathrm{C}$ per hour. Remaining roots were trimmed from the crowns and the crowns were dipped in 5\% Vitavax (Gustafson, Plano, TX), a fungicide, to inhibit the proliferation of microorganisms during recovery. The crowns were transplanted into soil mix in trays and allowed to grow for $21 \mathrm{~d}$ at $20^{\circ} \mathrm{C}$.

\section{Sample Collection for Histological Observations}

Plants recovering from the freeze test were removed from the soil at 3,10, and $21 \mathrm{~d}$ after freezing, rinsed in water, and photographed (Fig. 1C-1F), and the lower portion of the stem measuring about 2 to $3 \mathrm{~cm}$ was placed in fixative containing 18:1:1 parts of $70 \%$ ethyl alcohol to glacial acetic acid to formaldehyde. For each treatment, five samples were collected in separate vials. The collected samples were kept at room temperature for $48 \mathrm{~h}$ and transferred to $70 \%$ alcohol and kept at $4^{\circ} \mathrm{C}$ until they were processed for dehydration and embedding. As a control, nonhardened and cold-hardened plants were also collected.

\section{Dehydration, Infiltration, and Embedding}

Samples were dehydrated according to procedures outlined by Johansen (1940) using a series of ethanol and tertiary butyl alcohol solutions. We observed that subzero-hardened samples needed longer times (up to $48 \mathrm{~h}$ ) in tertiary butyl alcohol and paraffin before they were embedded. Otherwise, the samples were too soft and crumbled during sectioning in a rotary microtome. Fully infiltrated tissues were embedded in Paraplast Plus paraffin (Fisher Scientific, Hampton, NH). Embedded samples were kept in a refrigerator until they were sectioned.

\section{Sectioning and Mounting}

The embedded sample blocks were sectioned in a ReichertJung 2050 rotary microtome (Cambridge Instruments, Buffalo, NY) at a thickness of 15 microns. The resulting paraffin ribbon containing serial sections was placed on a glass slide coated with Haupt's adhesive (Johansen, 1940), flooded with 3\% formaldehyde, and transferred to a slide warmer at $41^{\circ} \mathrm{C}$. Dried slides were stored at room temperature until stained.

\section{Staining}

The slides were left overnight in dishes containing xylene to remove paraffin before sections were stained. A triple stain with Safranin, Fast Green, and Orange G (Fisher Scientific) was used as described by Johansen (1940). Safranin stains brilliant red in nuclei, chromosomes, and lignified and cutinized cell walls. Fast Green stains cellulose cell walls and also cytoplasm and mostly appears as blue to bluish-green. It also serves to remove reddish tinge of Safranin from tissues where its presence is undesirable. Orange- $G$ was used as a counter stain to differentiate between Safranin and Fast Green but, occasionally the cytoplasm stained orange. A cover-glass was added to slides with one or two drops of Permount adhesive (Fisher Scientific).

\section{Observation of Sections}

After drying for 1 or $2 \mathrm{~d}$, mounted sections were viewed with a Zeiss (Jena, Germany) Photomicroscope III to observe differences among the samples. Representative sections were viewed under a Wild Heerbrugg (Gais, Switzerland) wide angle dissecting microscope with bottom lighting. Photographs were taken with a Sony (Tokyo, Japan) DSC707 digital camera attached to the microscope.

\section{Crown Fractions}

Plants were taken for fractionation just before cold-hardening, and at 1, 2, and 3 wk of hardening. They were washed free of soil and roots and were trimmed to about $5 \mathrm{~cm}$. All subsequent fractionation was performed in a cold-room at $3^{\circ} \mathrm{C}$. Under $7 \times$ magnification, plants were lightly scored all the way around the stem with a razor blade just above the region of the crown where the roots protrude. With one hand tightly holding the roots and the other hand holding the lower leaf base, a slight twisting motion with a firm, slow pull allowed nearly a perfect separation of the stem and exposed the crown meristem (CM) complex (Fig. 1G, 1I). About 1 to $2 \mathrm{~mm}$ of tissue was trimmed from the top of the exposed CM complex (apical region, Fig. $1 \mathrm{H}$ ) and placed into one vessel of the calorimeter. The basal portion of the CM complex, consisting primarily of the crown core (Fig. 1J), was trimmed of roots, as close to the root-shoot junction as possible (Aloni and Griffith, 1991); it was not possible to perfectly remove all root tissue from the crown core, nor was it possible to remove all the outer layers of tissue from the basal portion of the $\mathrm{CM}$ complex. The crown core was placed into the other calorimeter vessel. When tissue from 16 plants had been fractionated and placed into tared aluminum inserts, fresh weight was recorded, inserts were placed in vessels, and vessels were inserted into the calorimeter precisely controlled at $-2.0^{\circ} \mathrm{C}$. One vessel contained approximately $30 \mathrm{mg}$ of apical region and the other $80 \mathrm{mg}$ of crown core. This procedure was repeated three times. All data are a mean of three replications and each replicate consisted of 16 plants.

\section{Thermal Analysis}

Fractionated crowns were studied in a Calvet Isothermal Calorimeter (Model MS 80; Setaram, Saint-Cloud, France) inside a small refrigerated room at $-10^{\circ} \mathrm{C}$. When the calorimeter was set to its full sensitivity (Seebeck circuit), $1 \mathrm{mV}$ output from the calorimeter equaled $17.6 \mathrm{~mW}$ displacement from baseline.

Samples were allowed to equilibrate at $-2.0^{\circ} \mathrm{C}$ in a supercooled condition until the baseline of the instrument stabilized $(6 \mathrm{~h})$. Freezing was initiated in both samples by inserting a hardened steel wire (guitar string) with a few crystals of ice adhering to the tip into the core of the calorimeter. The heat generated from inserting the wire was below the limits of detection for the settings used in these experiments. As the sample froze, the signal from the calorimeter was recorded on a strip chart recorder and areas under curves were measured using a hand-held planimeter. The average of three measurements (less than 3\% variation was observed between measurements) was used in all calculations. Areas under curves were calibrated using the latent heat of fusion of pure water (335 $\mathrm{J} \mathrm{g}^{-1}$ water). Initial freezing rates were calculated as the time to reach half full deflection of output from the calorimeter. 
After the latent heat was measured, aluminum inserts containing plant tissue were removed from the vessels and placed into an oven at $70^{\circ} \mathrm{C}$ for $16 \mathrm{~h}$ and dry weights were recorded. This value was used to determine the total amount of water in each sample. Percentage dry weight was calculated as the weight of dry tissue divided by the total fresh weight (before drying). Less than $1 \%$ of the total water was lost from the vessel during the freezing process.

\section{Scanning Electron Microscopy}

Samples were placed in the fixative described above, washed with several changes of $50 \%$ ethanol, dehydrated in graduated concentrations of ethanol, dried to the critical point in $\mathrm{CO}_{2}$, mounted on stubs, and sputter-coated with gold. Samples were observed and imaged using a Model JSM-6400V scanning electron microscope (JEOL, Peabody, MA) at 10 to $12 \mathrm{kV}$ of accelerating voltage.

\section{RESULTS AND DISCUSSION}

In cereal crops, the crown is a 5 - to $10-\mathrm{cm}$ section of the lower stem of the plant (Fig. 1G). The crown can be separated from the whole plant by partially trimming roots and leaves and has routinely been freeze-tested as a representative of the entire plant (Marshall, 1965; Olien, 1964; Livingston, 1996). If specific tissues within the crown are not damaged too severely by freezing, they will provide support to the stem and roots and the plant will regrow.

We have restricted our observations in this study to two portions of tissue within the crown, namely the upper portion, called the apical region, and the lower portion, which has been referred to as the scutellar node or cotyledonary plate in plants that are up to $5 \mathrm{~d}$ old (Avery, 1930; Boyd and Avery, 1936); we are calling this lower portion the "crown core" (Fig. 1J, 2A, 2B). The crown core is composed of an intertwining series of vascular bundles, fibers, and tracheids interspersed with parenchyma cells in a generally inverted cone shape. Pearce et al. (1998) provide a detailed description of the various tissue types within the crown and referred to this region as "the inner part of the sub-apical region" and "the inner part of the base of the crown." Together the apical region (Fig. $1 \mathrm{H}$ ) and the base of the crown (Fig. 1J) form what we have referred to as the "crown meristem (CM) complex" (Fig. 1I).

The arrangement of vessels in roots was nearly identical between plants; the same was true for leaves (not shown). However, vessel arrangement within the crown core was considerably different between plants (compare Fig. 2B, 3A, 4A). In root tissue, phloem cells were arranged in a ring on the outside of xylem vessels (Fig. 4B, 4E) (Esau, 1977) but in the crown core, phloem was found mostly surrounded by xylem vessels (Fig. 2D). The cells and tissues in the crown core appeared to lack a clear organizational pattern, particularly in plants with different tiller numbers. In many cases bundles of xylem and phloem cells, longitudinally sectioned, were adjacent to bundles in cross-section (Fig. 2D). Fibers and tracheids of the crown core were also positioned at different angles relative to each other (Fig. 2C). Interspersed throughout the crown in both the crown core and meristematic regions were numerous, relatively large parenchyma cells (Fig. 2A, 2B, 2C).

Nonhardened crown sections (Fig. 2A) appeared to have less lignified tissue in the crown core than coldhardened crowns (Fig. 2B) as evidenced by the lower intensity of Safranin-staining in cells. Apart from the difference in staining intensity, the overall size and concomitant complexity of the crown core was the only visible difference between plants that were nonhardened and those that were cold-hardened for $3 \mathrm{wk}$. There were no visible histological differences between plants that were cold-hardened and those that were subzerohardened (frozen at $-3^{\circ} \mathrm{C}$ for $3 \mathrm{~d}$; not shown).

\section{Freeze Damage}

Pearce and Fuller (2001) examined freezing in barley using infrared video thermography and reported that at $-2^{\circ} \mathrm{C}$ ice spread longitudinally in leaves and could have been associated with vascular bundles. This method did not resolve freezing of individual cells, however, so the exact cells in which freezing began could not be unequivocally determined (Pearce and Fuller, 2001). Despite this limitation, they presented evidence suggesting that initial freezing did not occur in the xylem vessels themselves but rather in extracellular spaces. They discussed a secondary freezing event at temperatures below $-2^{\circ} \mathrm{C}$ that caused additional damage but did not speculate on which specific cells were damaged.

The tearing observed in several vessels (Fig. 3C, 3D, compare with Fig. 2C, 2D) suggests that the cells were ruptured by intracellular freezing. Pearce and Fuller (2001) proposed that in leaves and stems freezing began in extracellular spaces and not in the xylem and that embolisms and nodal segmentation in stems delayed or prevented the spread of freezing. They suggested the purpose of these nodes in stems of cereal plants was to prevent the spread of ice into the crown (Pearce and Fuller, 2001). Since the plant in Fig. 3 is one that had been frozen at $-13^{\circ} \mathrm{C}$, it had progressed beyond an initial freeze and ice had clearly spread into the crown. Olien (1961) reported that when ice formed in barley crowns, water initially froze in xylem vessels, causing them to rupture, and as freezing progressed, damage spread to surrounding cells in the form of intracellular freezing as well as dehydration. Scanning electron microphotographs of freeze-treated rye crowns showed that in some cases cells were simply separated from neighboring cells and in other cases cells were torn open (our unpublished data).

\section{Three Days after Freezing}

An apparent contraction or possible disintegration of the nuclear envelope and a dark red appearance of the chromatin (Fig. 3B) was initially the most obvious effect of freezing and was also observed in plants that had been fixed immediately after freezing (Day 0 of recovery, not shown). An area of the crown consisting primarily of parenchyma cells of the ground meristem had normal nuclei toward the interior of the leaf base and cells with abnormal nuclei toward the exterior of the leaf base 


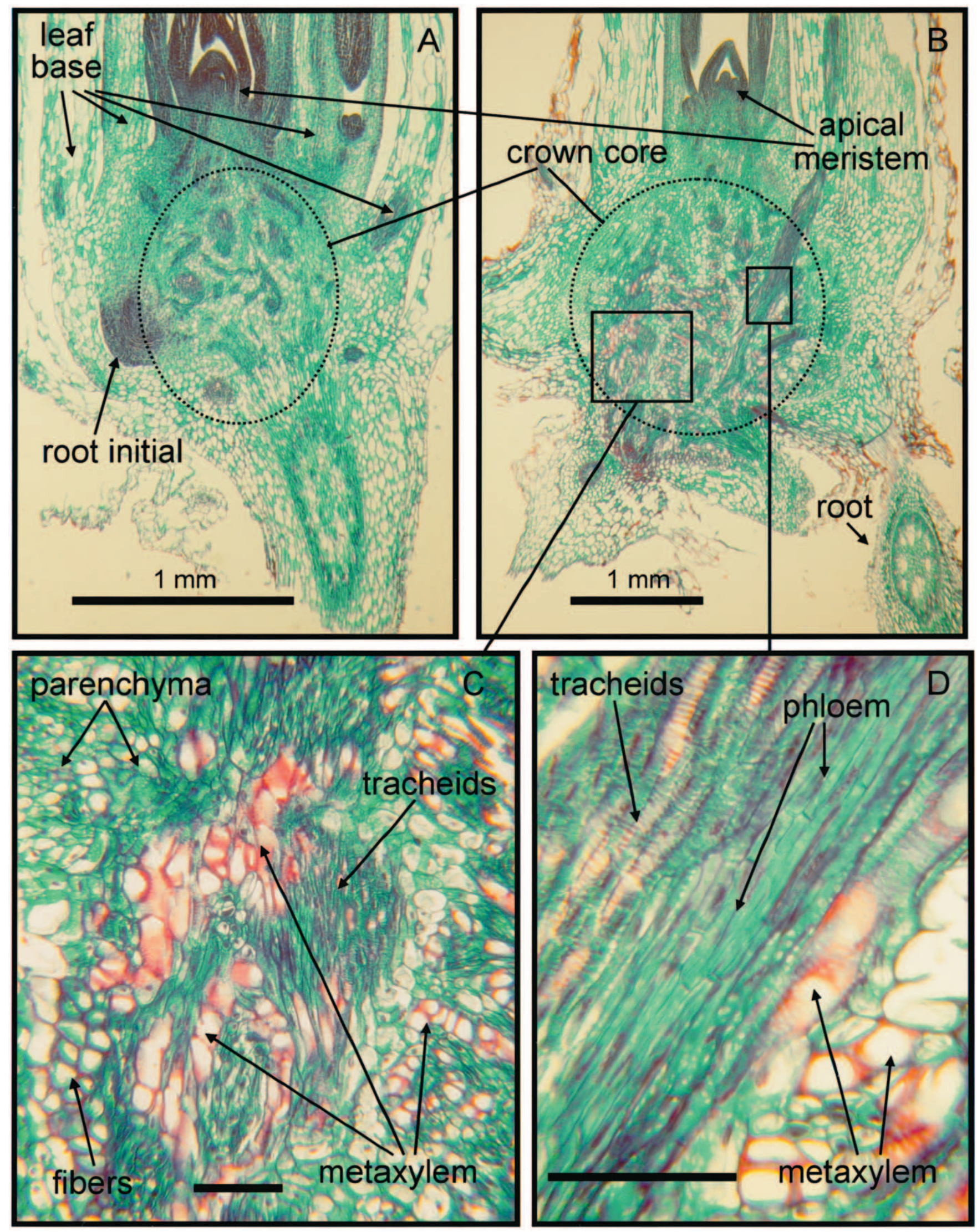

Fig. 2. (A) Longitudinal section stained with Safranin, Fast Green, and Orange G, of a 5-wk-old oat plant grown at $13^{\circ} \mathrm{C}$ under controlled conditions; this was a nonhardened plant corresponding to the plant " $A$ " in Fig. 1. (B) Longitudinal section of an oat plant grown for 5 wk at $13^{\circ} \mathrm{C}$ and then 3 wk at $3^{\circ} \mathrm{C}$ to induce cold-hardening; this section corresponds to the plant " $B$ " in Fig. 1 and is the control tissue to which all other sections were compared. (C) Part of the crown core showing parenchyma, tracheids, metaxylem, and fibers. (D) Part of the crown core showing a longitudinally sectioned vessel bundle. Note longitudinal metaxylem vessels adjacent to those in cross section. The unlabeled bar in each subpanel is $100 \mu \mathrm{m}$. 


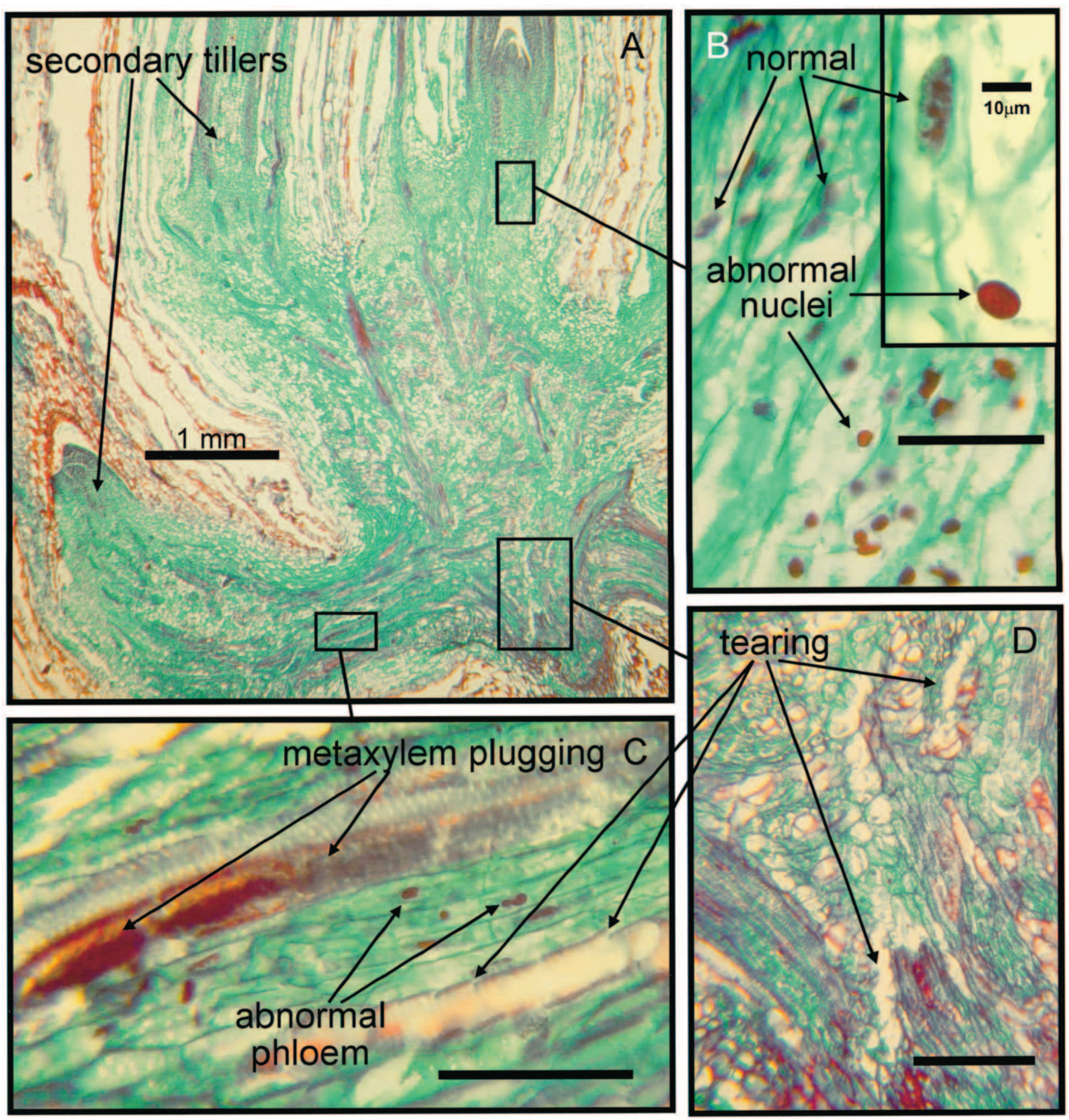

Fig. 3. (A) Longitudinal section stained with Safranin, Fast Green, and Orange $\mathbf{G}$, of a cold-hardened oat crown that had been frozen at $-11^{\circ} \mathrm{C}$ and then allowed to recover for $3 \mathrm{~d}$ at $13^{\circ} \mathrm{C}$ in planting medium. This section is from the plant in Fig. 1C. (B) Normal nuclei showing the somewhat grainy purple-blue color of the chromatin, and adjacent cells that contain abnormally condensed chromatin that stained a dark red color and lacked any clear internal definition. With a few exceptions, abnormal nuclei were primarily found in cells on the outside of stem bases. Inset: a closer view of two adjacent cells, one with a normal nucleus and the other with an abnormal one. (C) Phloem with abnormal nuclei and metaxylem beginning to plug with dark red material. Note tearing in the wall of the metaxylem vessel. (D) Tearing of tissue within the crown core. The unlabeled bar in each subpanel is $100 \mu \mathrm{m}$.

(Fig. 3B). However, no cells in the apical region, above the crown core, had abnormal nuclei (not shown in detail). Phloem cells, between plugged or torn metaxylem, had darkly stained nuclei (Fig. 3C) that were indicative of damage.

The darkly stained nuclei (Fig. 3B) were assumed to be an indicator of cells that had been damaged by freezing for the following reasons: (i) abnormal nuclei were observed mostly in cells directly adjacent to xylem vessels, presumably where ice formation began, (ii) altered nuclei were primarily visible in plants that had been frozen at $-13^{\circ} \mathrm{C}$ at which temperature most plants did 


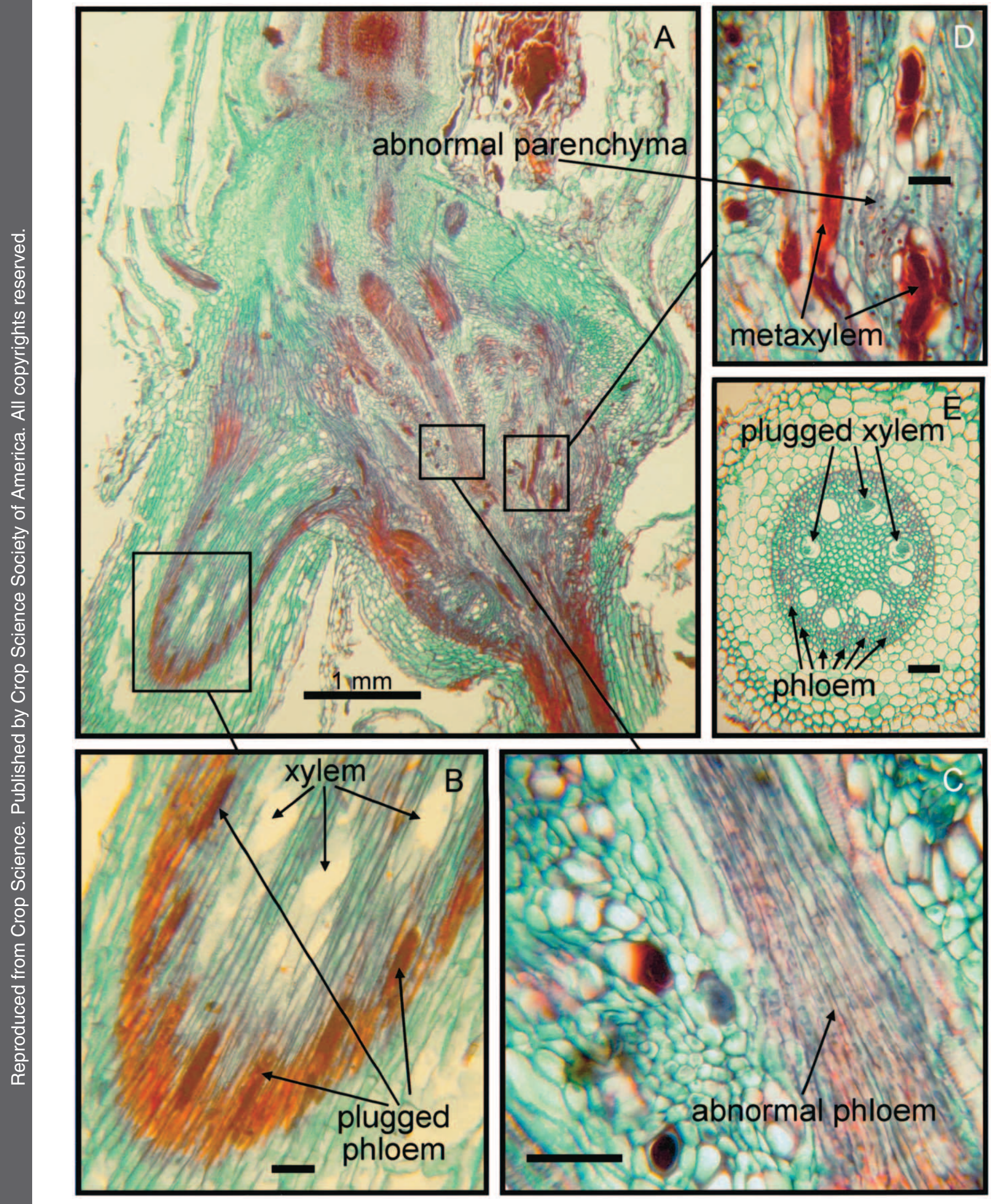

Fig. 4. (A) Longitudinal section stained with Safranin, Fast Green, and Orange G, of a cold-hardened oat crown frozen at $-13^{\circ} \mathrm{C}$ and then allowed to recover for $10 \mathrm{~d}$ at $13^{\circ} \mathrm{C}$ in planting medium. This section is from the plant in Fig. 1D. (B) A large root with plugged phloem, but in this case with no plugging in the xylem. (C) Abnormal phloem in the central part of the crown core. Note the lack of nuclei and reddish color as compared with the control (Fig. 2D). (D) Plugged metaxylem and parenchyma with abnormal nuclei as compared with control (Fig. 2C). (E) Cross-section of a small root from a different section of the same plant with several xylem vessels plugged. Most of the phloem vessels in a ring outside the xylem also appear plugged. The unlabeled bar in each subpanel is $100 \mu \mathrm{m}$. 
not survive (not shown), (iii) considerably fewer cells (primarily those adjacent to the epidermis) with abnormal nuclei were observed in plants frozen at $-11^{\circ} \mathrm{C}$ under which conditions most plants lived, and (iv) no abnormal nuclei were observed in any cells of coldhardened plants frozen at $-3^{\circ} \mathrm{C}$ (subzero-hardening) at which temperature all plants survived.

This effect on nuclei was similar to that described by Tzinger and Petrovskaya-Baranova (1970) in wheat recovering from freezing. However, their illustrations did not allow a satisfactory comparison with our results. Ewers (1982) shows nuclei in phloem of pine needles that resemble those we found (Fig. 3B). He describes them as abnormal but the abnormal nuclei he described were not a result of stress. Shibata and Shimada (1986) quantified damaged cells in crown tissue of orchardgrass (Dactylis glomerata L.) recovering from freezing and describe the cells as "degenerated and with nuclear pycnosis." They concluded that compared with control tissue, cells with nuclear pycnosis had been killed by freezing injury because they did not plasmolyze with $\mathrm{CaCl}_{2}$ and they stained a weaker color with neutral red in hand sections that had not been exposed to fixative (Shibata and Shimada, 1986). No detailed photograph of pycnotic nuclei was provided but in personal communication (2004) Shibata confirmed that the abnormal nuclei in Fig. 3B were very similar to what they described as "pycnosis of nuclei." Extensive research has been published on nuclear abnormalities in mammalian tissue exposed to various sources of radiation, high temperatures, severe dehydration, anesthetics, and different carcinogens (Cerqueira et al., 2004; Torres-Bugarin et al., 2003). Some of the abnormalities are described as "condensed chromatin and pycnosis" and appear equivalent to the nuclei shown in Fig. 3B.

Ashworth and Pearce (2002) reported that the mesophyll in leaf tissue of maize (Zea mays L.) was dehydrated during freezing, while the epidermis and bundle sheath were not. They speculated that this difference may have been due to a more rigid cell wall in the epidermis and bundle sheath, which could provide an opposing force to water loss and thus prevent desiccation. A cold-induced mRNA was expressed primarily in the vascular transition zone of the crown (Pearce et al., 1998). One of two other mRNAs was found primarily within epidermal tissue of the crown and leaves and a third mRNA was expressed only in the inner layers of the cortex and cell layers found in proximity to the vascular transition zone (Pearce et al., 1998). Houde et al. (1995) identified a late embryogenesis abundant protein family (WCS120) that has been associated with the development of freezing tolerance in wheat. They localized this protein family to the vascular transition zone of wheat crowns but none was found in meristems or in mature xylem. These results illustrate the importance of taking into account the characteristics of specific tissue, when speculating on reasons a plant might be freezing tolerant. Measuring biochemical and genetic differences at the single-cell level such as that described by Lu et al. (2002) and Haritatos et al. (2000) or at the tissue level (Houde et al., 1995; Pearce et al., 1998) is crucial if one is to thoroughly comprehend whole-plant freezing tolerance. Tissue-specific or even cell-specific analyses may also help explain much of the contradictory literature when various compounds extracted from whole plants or crowns are correlated to freezing tolerance.

\section{Ten Days after Freezing}

After $10 \mathrm{~d}$ of recovery, much of the damage seen at Day 3 appeared more advanced (Fig. 4A). At this stage the crown core appeared more reddish in color, possibly due to less Fast-Green-absorbing cellulose in wall material and more plugged xylem vessels (Fig. 4D). The tendency of cells to absorb Safranin and therefore produce an overall reddish appearance could also have been accentuated by the disappearance, from freeze-damaged cells, of cytoplasm that is stained primarily by Fast Green. These changes may be similar to differences described above between nonhardened and cold-hardened plants (Fig. 2A and B).

The nuclei of phloem in the crown core had disappeared after $10 \mathrm{~d}$ (Fig. 4C) and in some roots, phloem appeared to be plugged (Fig. 4B, 4E). This plugging was observed as early as the third day of recovery in metaxylem vessels (Fig. 3C). In some cross-sections, xylem vessels of roots had also filled with darkly staining material and appeared to be plugged (Fig. 4E). It is possible that vessel plugging is the result of a proliferation of microbes. Smith and Olien (1981) suggest that "organisms present in the healthy plant before freezing can multiply in the released cell contents and produce toxins or lyse cells not damaged by freezing." Alternatively, Tzinger and Petrovskaya-Baranova (1970) suggest that freezing causes protein coagulation and denaturation and the subsequent release of hydrolytic enzymes break down this coagulated protein, which eventually dissolves. Since the filling of xylem appears to increase during recovery rather than decrease, as would be expected from disintegration of coagulated protein, it seems more likely that microbial proliferation is the cause of the apparent plugging.

While plugged vessels and abnormal nuclei appeared throughout the crown core, much of the tissue at first glance seemed structurally sound and only by extending recovery for an additional $10 \mathrm{~d}$ could the full effect of freezing damage to the crown core be observed (Fig. 5 and 6).

\section{Dead Plant Three Weeks after Freezing}

Regrowth of new tissue in winter cereals occurs in the first 1 to $5 \mathrm{~d}$ after a freeze test but if the freeze test is severe enough, new growth will not continue beyond 8 or $10 \mathrm{~d}$ and the plant will die (Olien, 1961; our unpublished observation). The new growth at the top of the intact plant in Fig. 1C clearly illustrates this initial regrowth.

Figure 5 is a plant frozen at $-13^{\circ} \mathrm{C}$, which appeared completely dead (Fig. 1E). However, closer examination revealed portions of the crown that appeared to be still alive. Cells in the apical region, which at Day 1 showed 


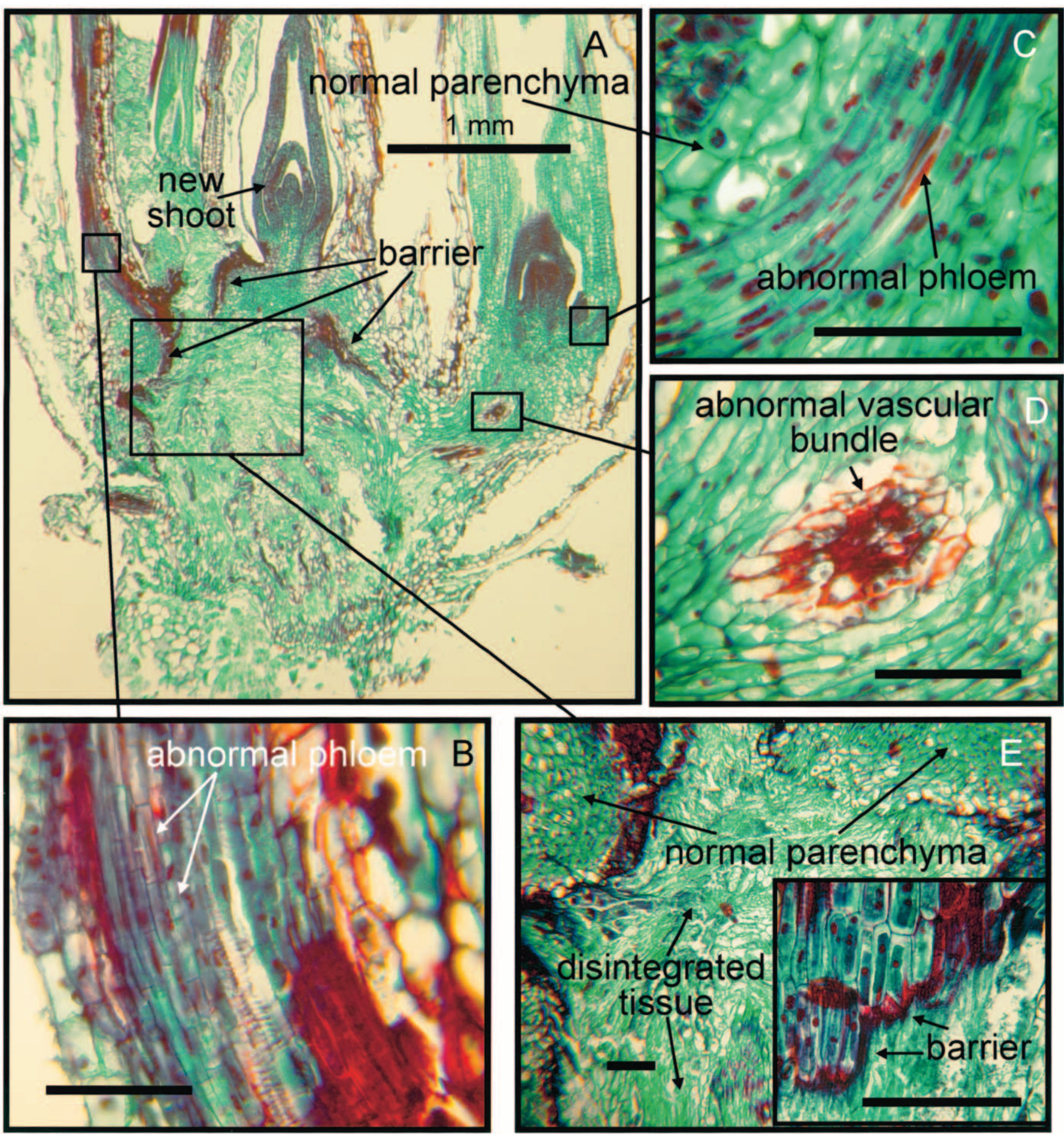

Fig. 5. (A) Longitudinal section stained with Safranin, Fast Green, and Orange G, of a cold-hardened oat crown frozen at $-13^{\circ} \mathrm{C}$ and then allowed to recover for $3 \mathrm{wk}$ at $13^{\circ} \mathrm{C}$ in planting medium. This section is from the plant in Fig. $1 \mathrm{E}$ that was rated as a nonsurvivor. Note that the whole plant appeared dead (Fig. 1E) but at 3 wk a seemingly new shoot had emerged. Note the dark staining region that forms what looks like a barrier between disintegrated tissue and normal tissue. (B) Abnormal phloem from leaf-base tissue. (C) Abnormal phloem from the leaf base of a tiller that had not been damaged as badly as the leaf base from the opposing tiller. (D) A vascular bundle in cross-section showing what appear to be plugged vessels as compared with controls in Fig. $2 \mathrm{C}$ and $2 \mathrm{D}$. (E) Interior portion of the crown core showing disintegrated cells with little evidence of structure. Inset: A closer view of the putative barrier from a different section of the same plant. Note the abnormal nuclei in the parenchyma cells outside the barrier. In this instance the barrier clearly did not prevent the occurrence of nuclear damage. The unlabeled bar in each subpanel is $100 \mu \mathrm{m}$.

no damage, still appeared integral and appeared to have given rise to a new shoot apex (Fig. 5A). However, with the exception of a few intact (but presumably nonfunctional) metaxylem vessels, all areas of the crown core had disintegrated with only the outline of various cells visible (Fig. 5A, 5E). Abnormal phloem (Fig. 5B, 5C) was observed in two tillers and vascular bundles appeared completely plugged (Fig. 5D). Regions of very 


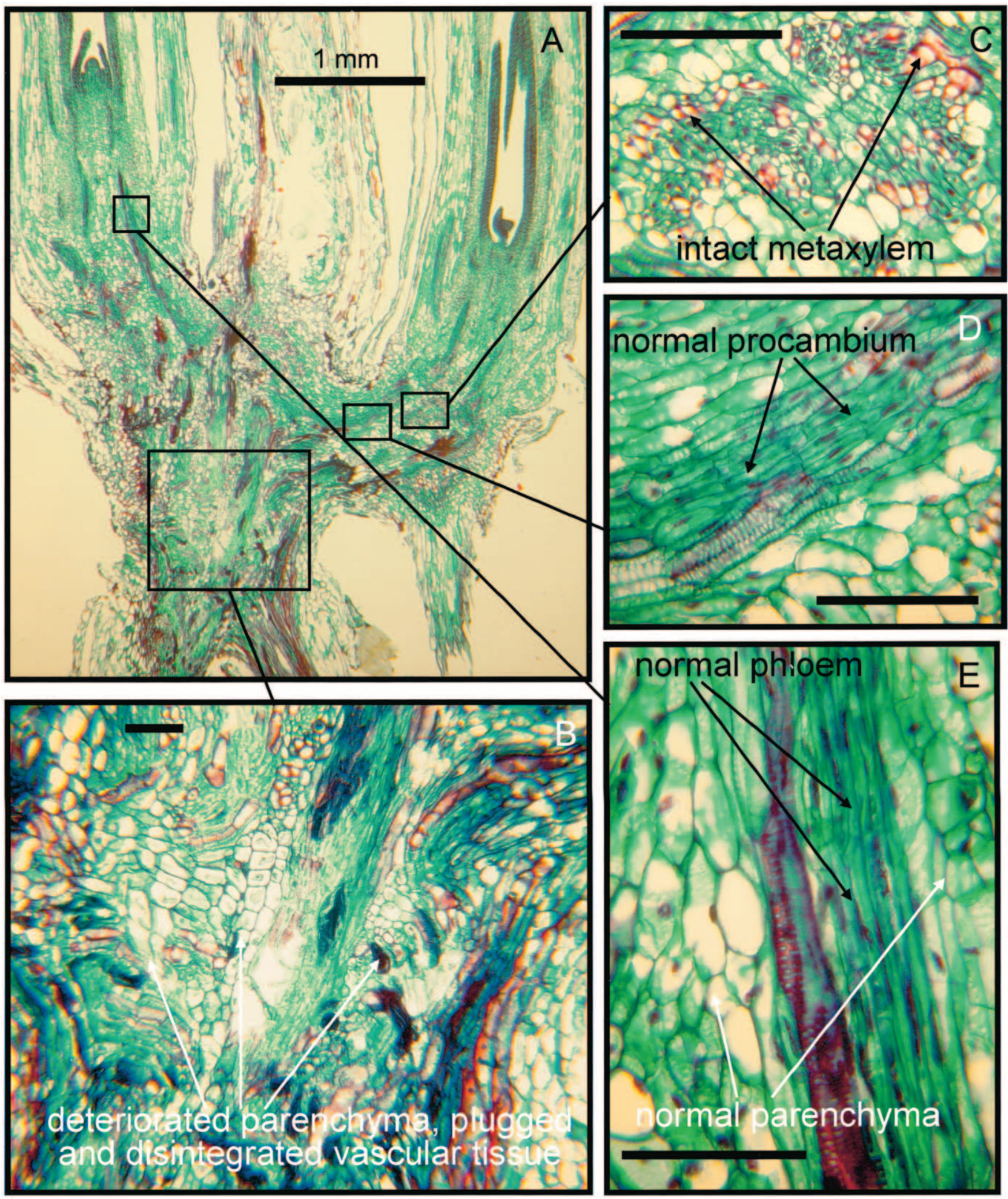

Fig. 6. (A) Longitudinal section stained with Safranin, Fast Green, and Orange $G$, of a cold-hardened oat crown frozen at $-13^{\circ} \mathrm{C}$ and then allowed to recover for $3 \mathrm{wk}$ at $13^{\circ} \mathrm{C}$ in planting medium. This section is from the plant in Fig. 1F. This plant survived the freeze test and would have produced functional reproductive tissue, despite extensive freeze-damage to the crown core (B). (C, D) Normal metaxylem, and procambium (immature xylem or phloem), from various parts of the crown core. (E) Normal phloem and parenchyma from a tiller that appeared to be elongating. The unlabeled bar in each subpanel is $100 \mu \mathrm{m}$. 
darkly staining material seemed to provide a demarcation between normal parenchyma of the meristematic region and the disintegrated tissue of the crown core (Fig. 5E). This darkly staining material was possibly the same substance as that plugging vessels described earlier, but we have no data to confirm this. Single and Marcellos (1981) reported that when wheat plants were frozen, the shoot apex (apical meristem) could not be induced to freeze at $-4^{\circ} \mathrm{C}$. They postulated that a barrier was present that restricted ice formation in the shoot apex. This may be similar to the barrier reported by Aloni and Griffith (1991) between roots and the crown core and described by Pearce and Fuller (2001). Nodal segmentation is clearly evident in stems of cereals (not shown) but, in unfrozen plants no histological barrier was visible between the crown core and the apical region (Fig. 2A, 2B). However, the layer of darkly staining material separating portions of the crown core and the apical region (Fig. 5A, 5E inset) suggests the presence of some type of barrier. This putative barrier clearly did not completely protect cells from freeze damage since parenchyma cells on the other side of the barrier in some cases had abnormal nuclei (Fig. 5E inset). The barrier could be something that prevents the spread of microbial growth after freezing and during recovery. More precise sampling will be crucial before speculating on the nature of such a barrier.

Without functioning vessels in the crown core to support the new apex or to support new roots, the tillers did not survive and the entire plant died (Fig. 1E). This would explain the initial growth after freezing (Fig. 1C), giving the appearance of survival, but subsequent death of the plant.

\section{Live Plant Three Weeks after Freezing}

The meristematic region above and surrounding the crown core was the most freezing-tolerant tissue in barley crowns (Olien, 1964; Smith and Olien, 1981) and in many cases could survive a freeze test despite the death of the crown core. The plant in Fig. 6 survived a freeze test at $-13^{\circ} \mathrm{C}$ and appeared undamaged after 3 wk (Fig. $1 \mathrm{~F})$. However, extensive disintegration of the crown core (Fig. 6A, 6B) was observed at this stage of recovery. Nevertheless, damage to the crown core was not severe enough to disrupt the ability of at least some vessels to provide material support to the meristematic tissue and the plant survived. Indeed much of the phloem above the crown core appeared to have normal cytoplasm and nuclei (Fig. 6D, 6E). None of the xylem above the damaged crown core appeared plugged (Fig. 6C, 6E).

Shibata and Shimada (1986) reported that the apical meristem of orchardgrass was less freezing tolerant than that of the lower crown. Pearce et al. (1998) reported differential survival of specific tissues in barley and found that the survival of the plant was highly correlated with tissue damage (as assessed by tetrazolium staining) in the "central area of the base" of the crown (presumably our "crown core"). Olien (1981) reported similar results in barley crowns. Tanino and McKersie (1985) reported that the apical meristem was the most tender tissue in nonhardened wheat crowns. However, by the time the plant had been cold-hardened for $3 \mathrm{wk}$, the most tender tissue was the crown core (Tanino and McKersie, 1985). They suggested that cold-hardening, therefore, occurs primarily in the apical meristem. Our results in oat support the finding that the hardiest tissue following cold-hardening is the apical region and underscores the problem with correlating various biochemical changes in the crown to the survival of the plant. For example, an extraction of water soluble components from an entire crown actually measures an average of all the tissue in the crown, while according to Tanino and McKersie (1985) cold-hardening occurs primarily, if not totally, within the apical meristem.

\section{Tissue Fractionation}

The CM complex (Fig. 1G, 1I) was separated from the rest of the crown and fractioned into two separate regions $($ Fig. $1 \mathrm{H}, 1 \mathrm{~J})$. While most of the tissue from the lower portion of the CM complex consisted of the crown core and is therefore referred to as such, a few outer layers of the base of the crown were also included. To see if differences between the two fractions could be detected we measured (i) dry weight, (ii) amount of water frozen, and (iii) initial freezing rates in the two fractions and compared them with each other. Despite the obvious difficulty of perfectly separating the tissue, all three measurements were consistently different in the two fractions.

\section{Dry Weight}

During cold-hardening, the percentage dry weight increased in both tissues but to a somewhat greater extent in the crown core than in the apical region (Fig. 7). In fact, the crown core always had a higher percentage dry weight than the apical region. Conversely, this meant that the apical region had a higher percentage of water than the crown core. Johansson and Krull (1970) reported that dry weight during cold-hardening in wheat

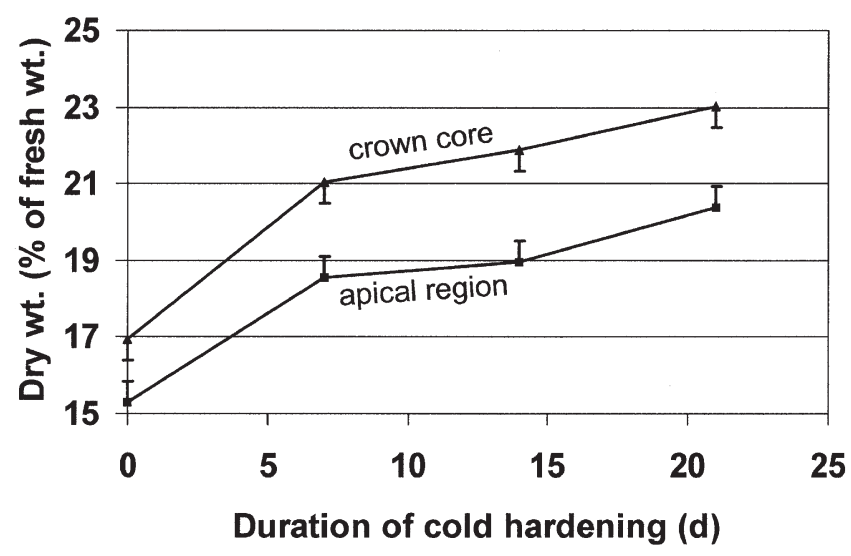

Fig. 7. A comparison between the apical region and crown core of the change in dry weight as a percentage of the fresh weight during cold-hardening. Each data point is the average of three experiments, each experiment consisting of tissue from 16 separate oat plants cold-hardened at $3^{\circ} \mathrm{C}$. Error bars represent the LSD at $p=0.05$. 


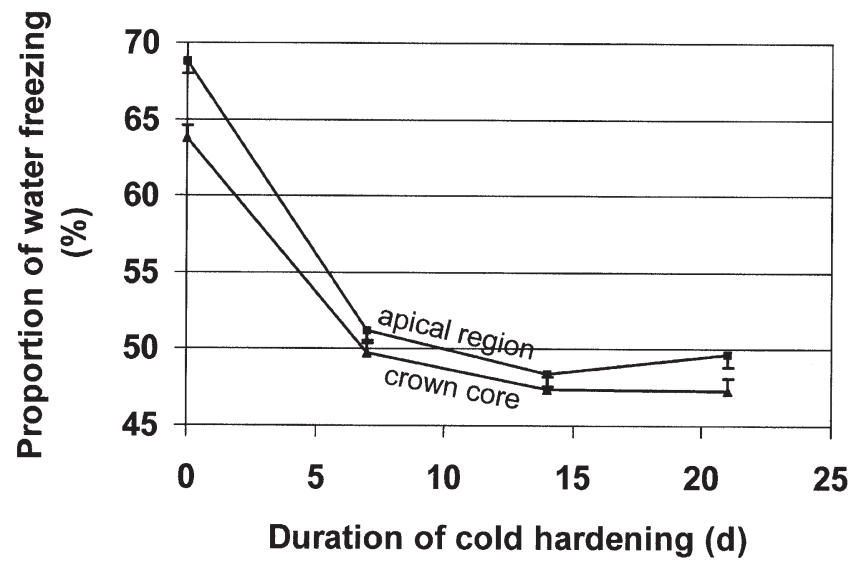

Fig. 8. Percentage of the total plant water that froze at $-2^{\circ} \mathrm{C}$ in fractionated tissue from oat crowns. Bars represent the LSD at $p=0.05$. increased from $12 \%$ in nonhardened plants to $22 \%$ in plants cold-hardened for $3 \mathrm{wk}$.

\section{Amount of Water Frozen}

The successful measurement of latent heat of freezing at a particular temperature is dependent on the ability both to super-cool the sample and to initiate freezing without disturbing the sample. Wheat, oats, and Arabidopsis were consistently super-cooled at $-2^{\circ} \mathrm{C}$ with no spontaneous freezing (our unpublished data). Both pure water and plant samples at $-2^{\circ} \mathrm{C}$ were induced to freeze with a few ice crystals adhering to the end of a narrowgauge wire (guitar string) inserted into the core of the calorimeter where the tissue samples were located. This inoculation procedure resulted in no detectable generation of heat at the sensitivity of these experiments. As-
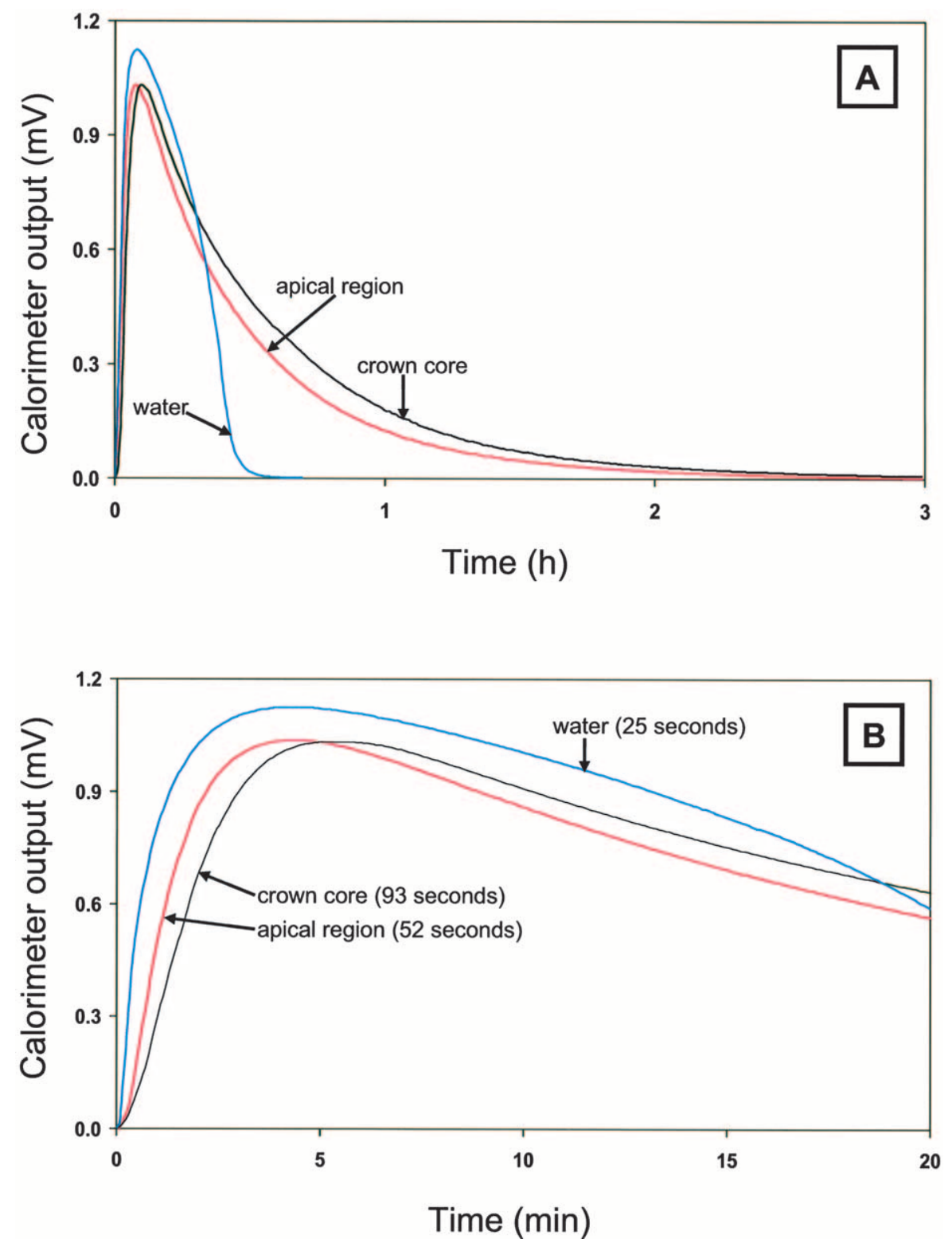

Fig. 9. Freezing curves of fractionated tissue from oat crowns (see Fig. 1) showing the latent heat of fusion at $-2^{\circ} \mathrm{C}$. For comparison, a separate freezing curve for $0.59 \mathrm{~g}$ of water was included with the freezing curves of the apical region and crown core. (A) The first $3 \mathrm{~h}$ of the 6-h freezing event. (B) The first 20 min of the same freezing event in (A) to show differences in initial freezing rates. 
suming other sources of heat were negligible in comparison with that generated by water crystallization and assuming interactions between ice and hydrophilic compounds such as membranes did not impact latent heat to an appreciable extent, the heat generated by water freezing provided an estimate of the net amount of water that froze at $-2^{\circ} \mathrm{C}$ (Fig. 8).

The difference between the apical region and crown core in the percentage of water freezing was significant $(p=0.05)$ in plants that were not cold-hardened (Fig. 8, Day 0). As the plants were exposed to cold-hardening the percentage of water freezing was reduced from 68 and $63 \%$ in the apical region and crown core, respectively, to $50 \%$ within 8 d (Fig. 8). After Day 8 little change was observed and the difference between the two tissues was not significant on Days 8 and 14. It is unlikely that the difference at Day 21 was biologically significant.

The percentage of water freezing at $-2^{\circ} \mathrm{C}$ by itself would not be expected to be directly related to wholeplant survival (Gusta et al., 1975) because the percentage of water freezing is a net result of all exothermic (freezing) and endothermic (melting) events in the respective tissue. One endothermic event is a result of $\mathrm{CO}_{2}$ dissolution in liquid water and subsequent outgassing (Livingston et al., 2000). Another endothermic event is a consequence of sugars being released into the apoplast of frozen plants (Olien, 1984; Livingston and Henson, 1998). Transcriptional profiling of mRNAs from Arabidopsis plants that were frozen at $-3^{\circ} \mathrm{C}$ for $3 \mathrm{~d}$ showed that more than $60 \mathrm{mRNA}$ sequences were up- or downregulated as compared with cold-hardened plants (our unpublished data). Many of these changes could potentially be important in water redistribution in the crown and if simply averaged together would prevent a clear understanding of the relationship between the amount of water freezing and the freezing tolerance of specific tissue. Studies have been initiated in Arabidopsis knock-out mutants of several of the most highly up-regulated sequences to clarify this complex relationship.

\section{Initial Freezing Rates}

The initial freezing rate of the apical region more closely resembled that of pure water than did that of the crown core (Fig. 9). This may have been due to the higher percentage of water (Fig. 7, lower percentage dry weight) in the apical tissue. The crown core always took about $2 \mathrm{~h}$ longer to completely freeze. Overall, the apical region apparently froze more quickly than the crown core. Pearce and Fuller (2001) reported that the spread of ice in young barley leaves was about twice as fast as that in older leaves. It is possible that more of the water in the crown core is within small pores as described by Ashworth and Abeles (1984) and simply took longer to freeze. It is also possible that many of the biochemical changes that affect the amount of water freezing (above) may also affect the initial freezing rate.

\section{CONCLUSIONS}

The reason for the apparent survival of the apical region in plants that are frozen at temperatures that destroy the integrity of the crown core (Fig. 5A, 5E) is not known. Differences in dry weight, amount of water freezing, and initial freezing rates indicate that fundamental differences exist between the two areas of the crown and suggest that crown-fractionation is preferable to averaging the entire crown when correlating biochemical and/or genetic adaptations with whole-plant freezing survival.

\section{REFERENCES}

Aloni, R., and M. Griffith. 1991. Functional xylem anatomy in rootshoot junctions of six cereal species. Planta 184:123-129.

Ashworth, E.N., and F.B. Abeles. 1984. Freezing behavior of water in small pores and the possible role in the freezing of plant tissues. Plant Physiol. 76:201-204.

Ashworth, E.N., and R.S. Pearce. 2002. Extracellular freezing in leaves of freezing-sensitive species. Planta 214:798-805.

Avery, G.S. 1930. Comparative anatomy and morphology of embryos and seedlings of maize, oats and wheat. Bot. Gaz. 89:1-39.

Boyd, L., and G.S. Avery. 1936. Grass seedling anatomy: The first internode of Avena and Triticum. Bot. Gaz. 97:765-779.

Cerqueira, E.M.M., I.S. Gomes-Filho, S. Trindade, M.A. Lopes, J.S. Passos, and G.M. Machado-Santelli. 2004. Genetic damage in exfoliated cells from oral mucosa of individuals exposed to X-rays during panoramic dental radiographies. Mutat. Res. 562:111-117.

Esau, K. 1977. Anatomy of seed plants. 2nd ed. Wiley Eastern Limited, New Delhi.

Ewers, F.W. 1982. Developmental and cytological evidence for mode of origin of secondary phloem in needle leaves of Pinus longaeva (bristlecone pine) and P. flexilis. Bot. Jahrb. Syst. Pflanzengesch. Pflanzengeogr. 103:59-88.

Gusta, L.V., M.J. Burke, and A.C. Kapoor. 1975. Determination of unfrozen water in winter cereals at subfreezing temperatures. Plant Physiol. 56:707-709.

Haritatos, E., B.G. Ayre, and R. Turgeon. 2000. Identification of phloem involved in assimilate loading in leaves by the activity of the Galactinol Synthase Promoter. Plant Physiol. 123:929-937.

Houde, M., C. Saniel, M. Lachapelle, R. Allard, S. Laliberte, and F. Sarhan. 1995. Immunolocalization of freezing-tolerance-associated proteins in the cytoplasm and nucleoplasm of wheat crown tissues. Plant J. 8:583-593.

Johansen, D.A. 1940. Plant microtechnique. McGraw-Hill, New York.

Johansson, N.O., and E. Krull. 1970. Ice formation, cell contraction and frost killing of wheat plants. Statens Vaextskyddsanst. Medd. 14:131-132.

Levitt, J. 1980. Responses of plants to environmental stress. Vol. 1. 2nd ed. Academic Press, San Diego, CA.

Livingston, D.P., III. 1991. Non-structural carbohydrate accumulation in winter oat crowns before and during cold-hardening. Crop Sci. 31:751-755.

Livingston, D.P., III. 1996. The second phase of cold-hardening: Freezing tolerance and fructan isomer changes in winter cereal crowns. Crop Sci. 36:1568-1573.

Livingston, D.P., III, and C.A. Henson. 1998. Apoplastic sugars, fructans, fructan exohydrolase and invertase in winter oat: Responses to second-phase cold-hardening. Plant Physiol. 116:403-408.

Livingston, D.P., III, C.R. Olien, and R. Premakumar. 2000. Thermal effect of $\mathrm{CO}_{2}$ on apoplastic ice in rye and oat during freezing. Plant Physiol. 122:861-865.

Lu, C., O.A. Koroleva, J.F. Farrar, J. Gallagher, C.J. Pollock, and A.D. Tomos. 2002. Rubisco small subunit, chlorophyll a/b binding protein and sucrose:fructan-6-fructosyl transferase gene expression and sugar status in single barley leaf cells in situ. Cell type specificity and induction by light. Plant Physiol. 130:1335-1348.

Marshall, H.G. 1965. A technique of freezing plant crowns to determine the cold resistance of winter oats. Crop Sci. 5:83-86. 
Olien, C.R. 1961. A method of studying stresses occurring in plant tissue during freezing. Crop Sci. 1:26-28.

Olien, C.R. 1964. Freezing processes in the crown of 'Hudson barley' Hordeum vulgare (L. emend. Lamn) Hudson. Crop Sci. 4:91-95.

Olien, C.R. 1981. Analysis of midwinter freezing stress. p. 35-58. In C.R. Olien and M.N. Smith (ed.) Analysis and improvement of plant cold hardiness. CRC Press, Boca Raton, FL.

Olien, C.R. 1984. An adaptive response of rye to freezing. Crop Sci. 24:51-54.

Pearce, R.S., and M.P. Fuller. 2001. Freezing of barley studied by infrared video thermography. Plant Physiol. 125:227-240.

Pearce, R.S., C.E. Houlston, K.M. Atherton, J.E. Rixon, P. Harrison, M.A. Hughes, and M.A. Dunn. 1998. Localization of expression of three cold-induced genes, blt101, blt4.9, and blt14 in different tissues of the crown and developing leaves of cold-acclimated cultivated barley. Plant Physiol. 117:787-795.

Shands, H.L., and W.H. Chapman. 1961. Culture and production of oats in North America. p. 465-529. In F.A. Coffman (ed.) Oats and oat improvement. ASA, Madison, WI.

Shibata, S., and T. Shimada. 1986. Anatomical observation of the development of freezing injury in orchardgrass crown. (In Japanese with English summary.) J. Jpn. Grassland Sci. 32:197-204.

Single, W.V., and H. Marcellos. 1981. Ice formation and freezing injury in actively growing cereals. p. 17-34. In C.R. Olien and M.N. Smith (ed.) Analysis and improvement of plant cold hardiness. CRC Press, Boca Raton, FL.

Smith, M.N., and C.R. Olien. 1981. Recovery from winter injury. p. 117-138. In C.R. Olien and M.N. Smith (ed.) Analysis and improvement of plant cold hardiness. CRC Press, Boca Raton, FL.

Steponkus, P.L. 1978. Cold hardiness and freezing injury of agronomic crops. Adv. Agron. 30:51-98.

Tanino, K.K., and B.D. McKersie. 1985. Injury within the crown of winter wheat seedlings after freezing and icing stress. Can. J. Bot. 63:432-435.

Torres-Bugarin, O., A. Ventura-Aguilar, A. Zamora-Perez, B.C. Gomez-Meda, M.L. Ramos-Ibarra, G. Morgan-Villela, A. GutierrezFranco, and G. Zuniga-Gonzalez. 2003. Evaluation of cisplatin + 5-FU, carboplatin + 5-FU, and ifosfamide + epirubicine regimens using the micronuclei test and nuclear abnormalities in the buccal mucosa. Mutat. Res. 539:177-186.

Tzinger, N.V., and T.P. Petrovskaya-Baranova. 1970. Autolytic processes in frozen plant tissues. Dokl. Akad. Nauk SSSR 194:437-440. 